\title{
3D Printing Process of Making a Smartphone Holder
}

\author{
Armita Dewi ${ }^{1}$, Hestiasari Rante ${ }^{1, *}$, Achmad Basuki ${ }^{1}$, Felix Pasila $^{2}$, and Michael Lund $^{3}$ \\ ${ }^{1}$ Department of Creative Multimedia Technology, Politeknik Elektronika Negeri Surabaya, \\ Jl. Raya ITS-Sukolilo, Surabaya 60111, East Java, Indonesia. \\ ${ }^{2}$ Electrical Engineering Department, Petra Christian University, Jl. Siwalankerto 121-131, \\ Surabaya 60236, East Java, Indonesia \\ ${ }^{3}$ Department of Computer Science, Universität Bremen, Bibliothekstraße 1, 28359 Bremen, Germany
}

\begin{abstract}
Smartphones have become a vital gadget that cannot be separated from human daily life. Various features provided on smartphones can attract attention, especially for children. Children today are very familiar with the smartphone. However, when they are using the smartphone, they often cannot manage the distance of eyes and the smartphone. Therefore, a smartphone holder that can control the distance can be a solution to this problem. The smartphone is designed with the flexibility to arrange the length of the stand depending on user needs. This paper presents the process of making the smartphone holder using a 3D printer. Through product development phase like design creation, digital simulation, computer aided design-computer aided manufacturing (CAD-CAM), and the production process of the holder with $3 \mathrm{D}$ printer, the smartphone holder is produced.
\end{abstract}

Keywords: 3D printer technology, additive manufacturing, computer aided design, computer aided manufacturing, digital simulations.

\section{Introduction}

One of the technologies that is increasingly developed lately is 3D printer technology. 3D printing, also known as additive manufacturing, is the process of making a three-dimensional solid object of virtually any shape from a digital model by built it in layers [1]. The first 3D Hull printer proved successful more than $30 \mathrm{yr}$ ago, in 1983. After the term "rapid prototyping" appeared, a description was given for the new unique Hull machine, "SLA-1," because it could be used to speed up making the required prototype. 3D printing is one of the breakthroughs in the manufacturing world. In the early 80 s it took 6 wk to 8 wk to make a prototype with a single-use tool, but with $3 \mathrm{D}$ printing it only took a few hours. The methods used in 3D printing are very diverse, but all begin with a computer-aided design (CAD) model or digital scanning. It is then processed by a slicer software that divides the object into several cross-sections which are added one above the other.

Extrusion uses a nozzle to make the object layer meet. Materials often used in 3D printers are thermoplastic materials such as acrylonitrile butadiene styrene (ABS), polycarbonate (PC), nylon, or bioplastic polylactic acid (PLA). Whatever material is used, it is usually sent

\footnotetext{
*Corresponding author: hestiasari@pens.ac.id
} 
to the print head as a solid, thin or filament which is then heated to a liquid state. 3D printers includes a set of components that opperate simultaneously to produce the desire outputfrom the input digital file, the basic components of 3D Printers are print bad (tray), noozle, extruder, hot-end and filament [2].

At present, this rapid prototyping technology is carried out in various fields of human activities, such as research, engineering, medical industry, military, construction, architecture, health, fashion, education, computer industry and various other industrial fields [3]. People can design anything and have it 3D-printed. The state of the art of 3D printing, especially for the production of implanted biomedical devices is limited by printed material. Therefore in many cases, alternative material processing methods are needed to be combined with materials that are not easily printed [4]. This paper will discuss the process of making smartphone holders using 3D printer technology in the manufacturing process. The smartphone holder is a tool that can be used to control the distance between eyes and the smartphone at an agreed distance. This holder is designed especially for children aged 6 yr old to 12 yr old.

\section{Theoretical basis}

\subsection{Modeling}

3D models that can be designed with Computer Assistance Packages (CAD), through 3D scanners, or with ordinary digital cameras and photogrammetric software. Software that can be used for the manufacturing process of the printed model is made with CAD software to reduce errors, can be corrected before being added and can be verified results before printing. This is not a simple process; abilities and experience are needed. The reverse engineering process is usually to copy, enhance, or adjust real objects, or also to combine complex surfaces into parts of 3D models [5].

\subsection{Technologies}

The technology used in the 3D printer machine depends on the procedure, material, and the performance and nature of the final product. There are three types of methods that are most widely used, including Fused Filament Fabrication (FFF), Stereolithography (SLA) and Selective Laser Sintering (SLS) [6]. The main difference that distinguishes these three technologies is in the raw materials used before the printing process.

FFF is the most commonly used method; the material used is a plastic known as a filament which is heated by the nozzle to make the desired layers. SLA uses liquid resin as the initial base while SLS starts with powder composite, which is melted to form a model. SLS uses powder compacted with lasers to make layers in the $3 \mathrm{D}$ printing process. There are two types of materials commonly used with this method, including plastic powder and metallic composite [6].

\section{Process}

The process of manufacturing in $3 \mathrm{D}$ printing is divided into four stage. This process, namely design process, digital simulation, computer aided design (CAD) to computer aided manufacturing (CAM), and printing. 


\subsection{Design 3D project}

The stages of making designs start from sketching ideas to the 3D design process. The sketch of the original idea was made using 2D Adobe Illustrator, while the $3 \mathrm{D}$ design creation process used Autodesk Inventor 2017. In the 3D design process, the actual size will represent the size of the product. Each part of the product is made in a different worksheet, and with the same size as possible. The goal is to get a visual of the product to be made.

Table 1. Size of each part of the holder.

\begin{tabular}{|c|c|l|}
\hline No. & \multicolumn{1}{|c|}{ Part } & \multicolumn{1}{|c|}{ Dimension } \\
\hline 1 & & $\begin{array}{l}\text { Diameter: } 18 \mathrm{~cm}, \text { Length: } 2 \mathrm{~cm}, \\
\text { Thick: } 3 \mathrm{~cm}\end{array}$ \\
\hline 2 & & $\begin{array}{l}\text { Length: } 25 \mathrm{~cm}, \text { Thick: } 2 \mathrm{~cm}, \\
\text { Wide: } 3 \mathrm{~cm}\end{array}$ \\
& & \\
\hline 3 & & Length: $28.2 \mathrm{~cm}$, Thick: $2 \mathrm{~cm}$, \\
& & \\
\hline
\end{tabular}

Then separate files are made into one assembly worksheet. The purpose of this coalition is to see whether each part can be combined. When an assembly file was made, this assembly (Figure 1) must be checked from $\mathrm{X}, \mathrm{Y}$, and $\mathrm{Z}$ axis. It is for minimizing error. Beside that, the dimension have to be rechecked to make sure that the dimension was correct.

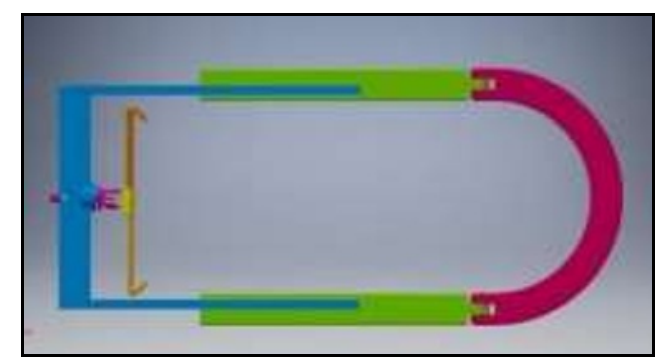

Fig. 1. Assembly design. 


\subsection{Digital simulations}

Displacement and strain simulations are performed when the holder is given the weight of a smartphone with a certain weight. Digital simulation is done using Autodesk Inventor. The first simulation is to look at the mesh and the second simulation is done to see the stress of the design tool that has been made. The purpose of digital simulation is to minimize errors before the product printing process. The results of the digital simulation are in Table 2 below.

Table 2. Digital simulation result.

\begin{tabular}{|c|c|l|}
\hline No & \multicolumn{1}{|c|}{ Picture } & \multicolumn{1}{|c|}{ Result } \\
\hline 1 & & $\begin{array}{l}\text { From the mesh simulation, it is known that } \\
\text { the number of points in the design is } \\
115119 \text { points, with } 69117 \text { elements }\end{array}$ \\
\hline 2 & & $\begin{array}{l}\text { From the results of stress analysis, it can } \\
\text { be seen that the minimum load is } 0, \text { while } \\
\text { the maximum load is } 0.66716 \mathrm{~kg} . \text { The } \\
\text { best load recommendations that can be } \\
\text { used are } 0.1336 \mathrm{~kg} \text { to } 0.2672 \mathrm{~kg} .\end{array}$ \\
\hline
\end{tabular}

\subsection{CAD to CAM}

Table 3. G-code output.

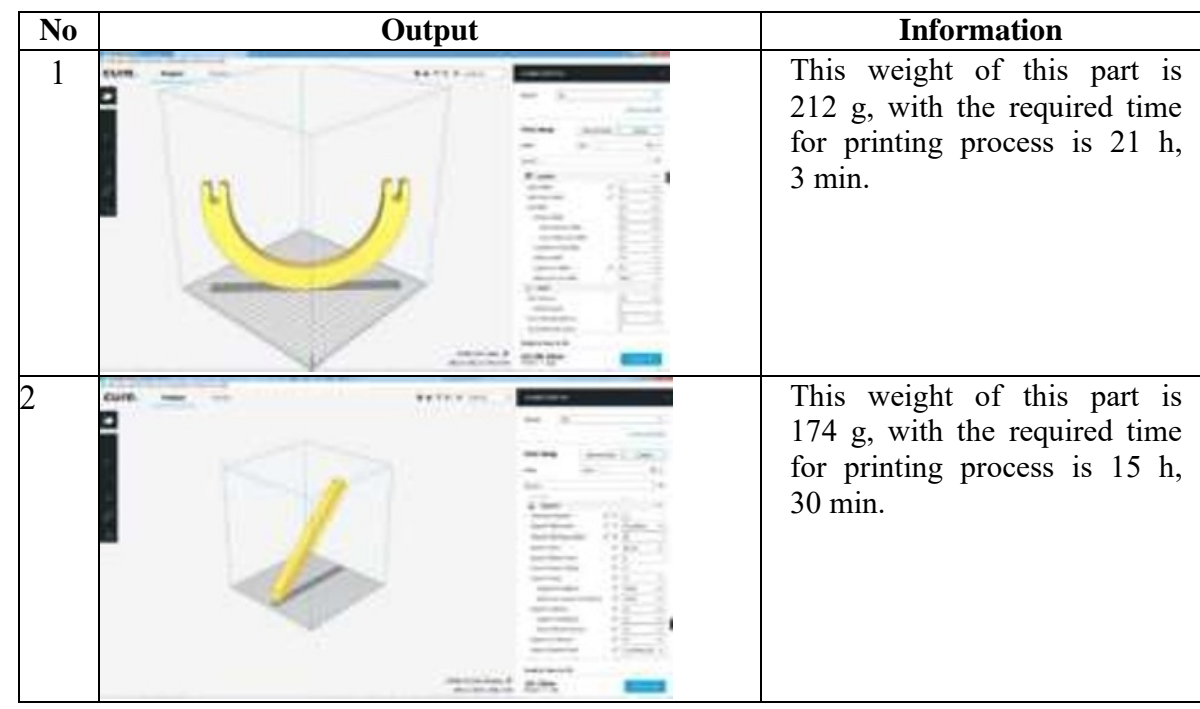

Table 3 . continue to the next page 
Table 3. (continued)

\begin{tabular}{|l|l|l|}
\hline No & \multicolumn{1}{|c|}{ Output } & \multicolumn{1}{|c|}{ Information } \\
\hline 3 & & \\
$208 \mathrm{~g}$, with of the require times \\
for printing process is $19 \mathrm{~h}$, \\
$50 \mathrm{min.}$
\end{tabular}

After a digital simulation, the file is exported in STL format. Then the file will be changed from CAD to CAM. CAD is the use of a wide range of computer-based tools that assist engineers, architects, and other design professionals in their design activities [7]. While CAM can be defined as the use of computer systems to plan, manage, and control the operations of a manufacturing plant through either direct or indirect computer interface with the plant's production resources [8]. CAD and CAM combination allows the transfer of information from the design into the stage of planning for the manufacturing of a product, without the need to reenter the data on part geometry manually. CAM systems are associated with computer numerical control (DNC) systems. The output of CAM is G-code. G-code is a compact, coded set of numbers automated manufacturing process that tell CNC machine for axis movements [9]. The software used to convert CAD to CAM files is Cura. From this process, how much the fill of each part can be set. For this holder, the infill of filament is $50 \%$. After the filaments were filled, information about the weight of each part and the length of time the holder can print the process can be obtained. For the results of this process can be seen at Table 3 .

\subsection{Printing}

After the design is sliced, the next process is the printing process. The filament used is an ABS filament with the Epson brand. While the 3D printer used Creality $\mathrm{Cr} 20$ Pro which has a density of 0.1 . The quality of the 3D-printed result is determined by various factors such as powder particle size, binder viscosity, droplet size, binder saturation, and printing layer thickness of 3D printer [10]. To facilitate the printing process, support is made during the printing process. Requires support structures to print parts with lower angles of 45 degrees. Support structures are used to maintaining the geometry of the $3 \mathrm{D}$ model intact since the polymer is heated can damage. Support can be removed by sanding or coating with other ingredients.

\section{Result}

After going through the process to produce a device called a smartphone holder (Figure 2) to control the distance between smartphones and eyes. The quality produced is very precise according to digital modelling design and size applied in CAD-CAM. This tool can be used with all types of smartphones, measuring 4.5 in to 6 in. It can be seen that the minimum load is 0 , while the maximum load is $0.66716 \mathrm{~kg}$. The best load recommendations that can be used are $0.1336 \mathrm{~kg}$ to $0.2672 \mathrm{~kg}$. Sliders from this tool can be extended to a distance of $40 \mathrm{~cm}$ with a minimum distance of $30 \mathrm{~cm}$. The weight of this product is about $800 \mathrm{~g}$. The time needed to make this product is around $2 \mathrm{~d}, 8 \mathrm{~h}, 23 \mathrm{~min}$. The 3D printer production process is not smooth, requires repeated trial-error, related to position orientation of printing and supporting structure of prints. The results of the printing process leave support on the sides, this support can be removed by sanding or coating with certain liquids. 
a.

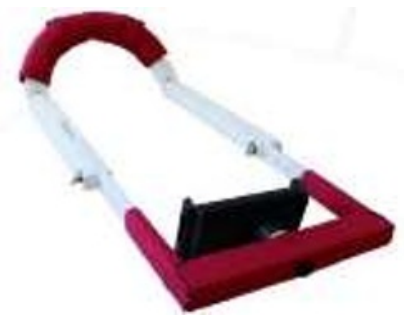

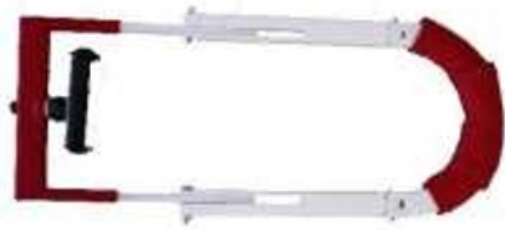

b.

Fig. 2. Product of smartphone holder. a) Front view b) Top view.

\section{Conclusion}

From the design process to the production printing process, it can be concluded that the quality of the 3D printer output depends on the quality of the material used and the quality of the $3 \mathrm{D}$ printer used. The process of digital simulation needs to be done to minimize errors in the results of printing. CAD is software to make $3 \mathrm{D}$ design; besides that CAM is software to connect with the machine. Support is required to keep maintain the geometry of the $3 \mathrm{D}$ model intact since the polymer is heated can damage. 3D printing has a limit. However, 3D printing has limitations in terms of the volume of products that can be printed.

\section{References}

1. T.P Mpofu, C. Mawere, M. Mukosera. IJSR 3,6:2148-2152(2014). https://www.semanticscholar.org/paper/The-Impact-and-Application-of-3D-PrintingMpofu-Mawere/6fb0de53006cfdf2efcfa79017170678efc5799a

2. S. Mkhemer. 3D printing technology. India: Briziet Univercity (2014). p. 4-5. https://www.researchgate.net/publication/272789911_3D printing

3. V.G Gokhare, D.N Raut, D.K. Shinde. IJERT, 6,6:953-958(2017). https://www.ijert.org/research/a-review-paper-on-3d-printing-aspects-and-variousprocesses-used-in-the-3d-printing-IJERTV6IS060409.pdf

4. H.N. Chia, B.M. Wu. J. Biol. Eng. 9,4:1-14(2015). https://jbioleng.biomedcentral.com/articles/10.1186/s13036-015-0001-4

5. Erasmus 3D Printing Vet Center. 3d printing technical guide [online] from https://www.e3dplusvet.eu/wp-content/docs/O1A1-EN.pdf (2017). [Accesed on 25th June 2019].

6. Leapfrog 3D Printers. 3d printing techniques and rapid prototyping. Netherlands: Leapfrog 3D Printers (2018). p. 19.

https://www.kyoceradocumentsolutions.com.au/Documents/3D\%20printing\%20Tech niques $\% 20$ Kyocera $\% 20$ Whitepaper $\% 202018 . p d f$

7. D. Mourtzis, S. Makris, G Chryssolouris. Computer-aided manufacturing. In: CIRP encyclopedia of production engineering. S. Chatti, L. Laperrière, G. Reinhart, T. Tolio (Eds). Berlin: Springer (2018).

https://link.springer.com/referenceworkentry/10.1007\%2F978-3-642-35950$7 \quad 6550-4$

8. E. Lutters. Computer-aided design. In: CIRP encyclopedia of production engineering. S. Chatti, L. Laperrière, G. Reinhart, T. Tolio (Eds). Berlin: Springer (2018). http://springer.iq-technikum.de/referenceworkentry/10.1007\%2F978-3-64235950-7 6443-4 
9. S.J. Shin, S.H. Suh, I. Stroud. Computer-Aided Design 39,1:1-16(2007). https://www.sciencedirect.com/science/article/abs/pii/S0010448506001667

10. M. Vaezi, C.K. Chua. Int. J. Adv. Manuf. Tech. 53,1-4:275-284(2011). https://link.springer.com/article/10.1007/s00170-010-2821-1 